\title{
Neuroprotective effects of dexmedetomidine against the ketamine-induced disturbance of proliferation and differentiation of developing neural stem cells in the subventricular zone
}

\section{Huanhuan Sha}

first affiliated hospital with nanjing medical university

\section{Peipei Peng}

first affiliated hospital with nanjing medical university

\section{Bing Li}

jiangning hospital of traditional Chinese medicine

\section{Guohua Wei}

first affiliated hospital with nanjing medical university

\section{Juan Wang}

first affiliated hospital with nanjing medical university

\section{Yuqing Wu}

Jiangsu Province Key Laboratory of Anesthesiology

he huang ( $\nabla$ 353550575@qq.com)

first affiliated hospital with Nanjing medical university https://orcid.org/0000-0003-1573-1204

\section{Research article}

Keywords: Dexmedetomidine, Neural stem cells, Subventricular zone, Neuroprotection, Ketamine

Posted Date: February 17th, 2020

DOI: https://doi.org/10.21203/rs.2.23770/v1

License: (c) (1) This work is licensed under a Creative Commons Attribution 4.0 International License.

Read Full License

Version of Record: A version of this preprint was published at Frontiers in Pediatrics on July 27th, 2021. See the published version at https://doi.org/10.3389/fped.2021.649284. 


\section{Abstract}

Background: Recent years, the number of neonatal patients receiving surgery under general anesthesia is increasing. Previous studies have indicated that ketamine can disturb the proliferation and differentiation of developing neural stem cells (NSCs). Therefore, the safe use of ketamine in pediatric anesthesia has drawn great concern among anesthesiologists and children's parents. Dexmedetomidine (DEX) is widely used in sedation, antianxiety and analgesia. Recent studies have shown that DEX could provide neuroprotection against anesthetic-induced neurotoxicity in the developing brain. The aim of this in vivo study was to investigate whether DEX had neuroprotective effects on the proliferation and differentiation of NSCs in the subventricular zone (SVZ) following neonatal ketamine exposure.

Methods: Postnatal day 7 (PND-7) male Sprague-Dawley rats were equally divided into the following 5 groups: Control group ( $n=8)$, ketamine group ( $n=8), 1 \mu \mathrm{g} / \mathrm{kg} D E X+$ ketamine group $(n=8), 5 \mu \mathrm{g} / \mathrm{kg}$ DEX+ketamine group $(n=8)$ and $10 \mu \mathrm{g} / \mathrm{kg}$ DEX+ketamine group $(\mathrm{n}=8)$. The proliferation and differentiation of NSCs in the SVZ were assessed by immunostaining with BrdU incorporation.

Results: Neonatal ketamine exposure significantly inhibited NSC proliferation and astrocytic differentiation in the SVZ, and neuronal differentiation was markedly promoted. Furthermore, DEX pretreatment reversed the ketamine-induced disturbances in the proliferation and differentiation of NSCs at moderate $(5 \mu \mathrm{g} / \mathrm{kg})$ or high doses $(10 \mu \mathrm{g} / \mathrm{kg})$.

Conclusion: Our findings demonstrate that DEX may have neuroprotective effects on NSCs in the SVZ of neonatal rats in a repeated ketamine anesthesia model.

\section{Background}

Ketamine is widely used in analgesia and sedative processes during pediatric examination and surgical operation [1-2]. Recently, an increasing number of research have suggested that neonatal ketamine exposure could cause neuroapoptosis and disturb normal neurogenesis in the developing brain and increase the risk of delayed neurocognitive dysfunction [3-6]. The evidence from clinical studies also supported that ketamine had long-term adverse effects on the neurocognitive function in children and infants [7-8]. Relevant research conclusions have prompted anesthesiologists to reevaluate the safety of using ketamine in pediatric anesthesia and to look for possible protective measures.

Dexmedetomidine (DEX), a highly selective $\mathrm{a}_{2}$-adrenoceptor agonist, is widely used for anxiolytic, sedative and analgesic in clinical pediatric anesthesia and intensive care [9-10]. DEX has shown protective effects on vital organs, including the decrease in lung and kidney damage and the reduction in neural apoptosis [11-12]. In anesthesia models of neonatal animal, DEX has been proven to produce protective effects on inhalation anesthetics-induced neurotoxicity in the developing brain [13-14]. In the clinical pediatric anesthesia, a medication strategy with DEX is increasingly being accepted as a way to reduce the adverse effects of ketamine [15-16]. However, the potential neuroprotective pathway of DEX needs to be further investigated. 
Neurogenesis in the hippocampus and subventricular zone (SVZ) are important processes in the developing brain [17-18]. Early disruption of these regions has an adverse potential to alter the formation of neural circuits [19]. At present, little is known about whether DEX has protective effects on the ketamine-induced neurotoxicity of NSCs in SVZ. Therefore, the aim of this study was to investigate the impact of DEX pretreatment on neurogenesis in the SVZ in a repeated ketamine exposure model of neonatal rats, including detecting the proliferation capacity of NSCs and neuronal and astrocytic differentiation.

\section{Materials And Methods}

\section{Animals and drug administration}

All animal procedures were approved by the Institutional Animal Care and Use Committee of NanJing Medical University. Timed-pregnant Sprague-Dawley rats were housed at $24^{\circ} \mathrm{C}$ on a 12-h light/dark cycle with free access to food and water. The postnatal day 7 (PND-7) male rats $(11-14 \mathrm{~g})$ selected from all the pups were used in the experiments.

Ketamine and dexmedetomidine (DEX, HengRui Pharma, China) were dissolved in $0.9 \%$ normal saline. The rat pups were randomly divided into 5 groups: (1) Control group (CON): the rats received an equal volume of saline $(n=8)$; (2) ketamine group (KET): the rats were administered intraperitoneally with four injections of $40 \mathrm{mg} / \mathrm{kg}$ ketamine with 1-h intervals $(40 \mathrm{mg} / \mathrm{kg} \times 4)(\mathrm{n}=8)$; (3) DEX 1 plus ketamine group (KET + DEX 1): the rats were pretreated with $1 \mu \mathrm{g} / \mathrm{kg}$ DEX intraperitoneally for $30 \mathrm{~min}$ prior to ketamine anesthesia $(40 \mathrm{mg} / \mathrm{kg} \times 4)(\mathrm{n}=8)$; (4) DEX 5 plus ketamine group (KET + DEX 5): the rats were pretreated with $5 \mu \mathrm{g} / \mathrm{kg}$ DEX intraperitoneally for $30 \mathrm{~min}$ prior to ketamine anesthesia $(40 \mathrm{mg} / \mathrm{kg} \times 4)(\mathrm{n}=8)$; (5) DEX 10 plus ketamine group (KET + DEX 10): the rats were pretreated with $10 \mu \mathrm{g} / \mathrm{kg}$ DEX intraperitoneally for $30 \mathrm{~min}$ prior to intraperitoneal ketamine anesthesia $(40 \mathrm{mg} / \mathrm{kg} \times 4)(\mathrm{n}=8)$. Custom-made temperature probes were used to facilitate control of temperature at $36.5 \pm 1{ }^{\circ} \mathrm{C}$ using computer-controlled heater/cooler plates integrated into the chamber floor. Between each injection, animals were returned to their chamber to help maintain body temperature and reduce stress. We found that four injections of $40 \mathrm{mg} / \mathrm{kg}$ ketamine with $1 \mathrm{~h}$ intervals could exert the satisfactory anesthesia effect and all animals in each group could survive after the anesthesia.

To ensure that hypoxia did not occur during anaesthesia in all newborn animals, arterial blood $(0.25 \mathrm{ml})$ gas determination was performed by cardiac puncture immediately after the end of anesthesia through a 30-gauge needle ( 6 animals per group). Arterial blood gases were measured with a portable clinical analyzer (GEM Premier 3000 USA).

\section{BrdU injections}

Immediately after the treatment of each group, the rat received a single intraperitoneal injection of $\mathrm{BrdU}$ (5-bromo-2-deoxyuridine; Sigma, $100 \mathrm{mg} / \mathrm{kg}$ ) in $0.9 \% \mathrm{NaCl}$ solution. The animals were anesthetized with 
an overdose of chloral hydrate and fixed by perfusion at $24 \mathrm{~h}$ after BrdU injection. The detailed experimental protocol is listed in Table 1.

Table 1

Experimental Protocol (8 tissue sections per group).

\begin{tabular}{|c|c|c|c|}
\hline Targeted Process & $\begin{array}{l}\text { BrdU Injections } \\
\text { Timing/Dose (mg/kg) }\end{array}$ & Interval to Perfusion & IF Stain \\
\hline $\begin{array}{l}\text { NSC proliferation } \\
\text { Neuronal differentiation } \\
\text { Astrocytic differentiation }\end{array}$ & $\begin{array}{l}\text { PND-7/100 } \\
\text { PND-7/100 } \\
\text { PND-7/100 }\end{array}$ & $\begin{array}{l}24 \mathrm{~h} \text { (PND-8) } \\
24 \mathrm{~h} \text { (PND-8) } \\
24 \mathrm{~h}(\text { PND-8) }\end{array}$ & $\begin{array}{l}\text { BrdU } \\
\beta \text {-tubulin III/BrdU } \\
\text { GFAP/BrdU }\end{array}$ \\
\hline
\end{tabular}

\section{Tissue preparation and immunofluorescence}

The brain of rats was isolated, removed and fifixed using $4 \%$ paraformaldehyde fixative for $6 \mathrm{~h}$. Then, the brain was embedded using medium on ice and stored at $-80^{\circ} \mathrm{C}$. The coronal brain sections were cut on a microtome at a thickness of $30 \mu \mathrm{m}$. When the SVZ was initially exposed in the slice, we selected three successive brain slices after each cut and a total nine brain slices were collected in each rat.

Immunofluorescence procedures were conducted as described in our previously reported methods [5]. The sections were incubated with $50 \%$ formamide in PBS for $2 \mathrm{~h}$ at $65^{\circ} \mathrm{C}$ preceded $2 \mathrm{~N}$ hydrochloric acid incubation for 30 min at $45^{\circ} \mathrm{C}$ and 3 washes with PBS for 10 min. Blocking of nonspecific epitopes with $10 \%$ donkey serum in PBS with $0.3 \%$ Triton-X for $2 \mathrm{~h}$ at RT preceded incubation overnight at $4{ }^{\circ} \mathrm{C}$ with the appropriate primary antibody (Table 2) in PBS with $0.3 \%$ Triton-X. After 3 washes with PBS, the sections were incubated with the suitable secondary fluorescent antibodies (Alexa 488-labeled donkey anti-rabbit and Alexa 594-labeled donkey anti-mouse; 1:200; Invitrogen) for $2 \mathrm{~h}$ at room temperature.

Table 2

Primary Antibodies.

\begin{tabular}{|llll|}
\hline Raised Against & Supplier & Raised in & Dilution \\
\hline BrdU & Sigma & Mouse, monoclonal & $1: 1000$ \\
GFAP & Millipore & Rabbit, monoclonal & $1: 200$ \\
$\beta$-tubulin III & Abcam & Rabbit, polyclonal & $1: 100$ \\
\hline $\begin{array}{l}\text { List of primary antibodies, their suppliers, the animal used to raise the antibodies in, and the working } \\
\text { dilution. }\end{array}$ & & \\
\hline
\end{tabular}

\section{Immunofluorescence area quantifification}

The sections were observed by a skilled pathologist blinded to this research using image stacks on a laser scanning confocal microscope (Fluoview 1000, Olympus). For each sample, we selected three sections for immunofluorescence of BrdU, three sections for immunofluorescence of $\beta$-tubulin III/BrdU 
and three sections for immunofluorescence of GFAP/BrdU respectively. The fluorescence area was measured using Image J (from the National Institutes of Health, Bethesda, MD, USA).

\section{Statistical analysis}

The data about proliferation and differentiation of NSCs were expressed as the medians and interquartile ranges (IQRs). The results about blood gas were expressed as mean \pm SD. The statistical analysis and the graphs were generated using GraphPad Prism 5. Significant differences between the groups were analyzed by one-way ANOVA. $P<0.05$ was considered statistically significant.

\section{Results}

\section{The arterial blood gas analyses}

In the experiment, all rats in each group survived until the end of the experiment. We observed that the animals' skin was ruddy and that the respiration was smooth. There were no significant changes in the $\mathrm{pH}, \mathrm{pCO}_{2}$ and $\mathrm{pO}_{2}$ in any groups (Table 3 ).

Table 3

The arterial blood gases analyse ( 6 animals per group)

\begin{tabular}{|c|c|c|c|c|c|}
\hline Parameter & 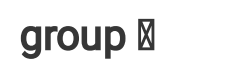 & 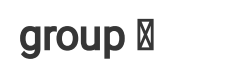 & 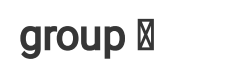 & 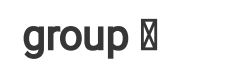 & 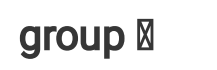 \\
\hline $\mathrm{pH}$ & $7.39 \pm 0.02$ & $7.41 \pm 0.03$ & $7.41 \pm 0.03$ & $7.42 \pm 0.04$ & $7.42 \pm 0.04$ \\
\hline $\mathrm{P}_{\mathrm{CO} 2}{ }^{\mathrm{a}}(\mathrm{mmHg})$ & $39.3 \pm 1.4$ & $39.1 \pm 1.7$ & $38.0 \pm 2.1$ & $40.0 \pm 2.3$ & $39.8 \pm 2.6$ \\
\hline $\mathrm{P}_{\mathrm{O} 2}{ }^{\mathrm{b}}(\mathrm{mmHg})$ & $168.0 \pm 3.1$ & $166.0 \pm 4.4$ & $163.3 \pm 4.5$ & $164.8 \pm 5.1$ & $162.2 \pm 4.0$ \\
\hline \multicolumn{6}{|c|}{ a $\mathrm{PcO}_{2}$ pressure carbon dioxide. } \\
\hline $\mathrm{b} \mathrm{Po}_{2}$ pressure & ggen. & & & & \\
\hline
\end{tabular}

\section{The effects of ketamine on the proliferation and differentiation of NSCs in the SVZ}

According to our previous studies, BrdU immunofluorescence was used to evaluate the proliferation capacity of NSCs in the SVZ. When $100 \mathrm{mg} / \mathrm{kg} \mathrm{BrdU}$ was injected immediately after anesthesia in PND-7 rats, we observed a drastic reduction in the number of $\mathrm{BrdU}^{+}$cells per SVZ in the ketamine group (median [IQR]: 28900 [26500-30750]) compared to that in the control group (median [IQR]: 44435 [42450-47408], shown in Fig. $1 A$ and $1 B, n=8, p<0.01$ ). It was suggested that neonatal ketamine exposure inhibited NSC proliferation in the SVZ. 
NSCs have the ability to differentiate into neurons, and the early neuronal marker associated with differentiation is $\beta$-tubulin III. BrdU ${ }^{+}$cells coexpressing the neuronal marker $\beta$-tubulin III were used to present the neuronal differentiation of NSCs. In this study, we found that the proportion of $\beta$-tubulin $\mathrm{III}^{+} / \mathrm{BrdU}^{+}$cells to $\mathrm{BrdU}^{+}$cells in the ketamine group (median [IQR]: 19.05\% [18\%-19.725\%]) was increased compared to that in control animals (median [IQR]: 13.15\% [12.475\%-13.7\%]) at $24 \mathrm{~h}$ after BrdU injection (Fig. $2 A$ and $2 B, n=8, p<0.01$ ).

The proportion of $\mathrm{BrdU}^{+}$cells coexpressing GFAP was introduced to show astrocytic differentiation of NSCs. The proportion of $\mathrm{GFAP}^{+} / \mathrm{BrdU}^{+}$cells to $\mathrm{BrdU}^{+}$cells at $24 \mathrm{~h}$ after BrdU injection was significantly greater in control rats (median [IQR]: 16.3\% [15.925\%-16.925\%]) than in ketamine-anesthetized rats (median [IQR]: 11.35\% [10.775\%-11.975\%], shown in Fig. 3A and 3B, $n=8, p<0.01$ ). It was suggested that neonatal ketamine exposure significantly promoted neuronal differentiation and attenuated the astrocytic differentiation of NSCs in the SVZ.

\section{Dexmedetomidine protects NSCs from ketamine-induced injury}

Next, we investigated the impact of dexmedetomidine (DEX) on the ketamine-induced disturbance of the proliferation and differentiation of NSCs in the SVZ. As shown in Fig. 1D and 1E, our findings suggested that pretreated with $5 \mu \mathrm{g} / \mathrm{kg}$ DEX or $10 \mu \mathrm{g} / \mathrm{kg}$ DEX before ketamine anesthesia could significantly increase the number of $\mathrm{BrdU}^{+}$cells per SVZ compared to that in the ketamine group (median [IQR]: 35900 [35025-36950] in the $5 \mu \mathrm{g} / \mathrm{kg}$ DEX plus ketamine group, median [IQR]: 41100 [38925-43368] in the $10 \mu \mathrm{g} / \mathrm{kg}$ DEX plus ketamine group, vs. median [IQR]: 28900 [26500-30750] in the ketamine group, $\mathrm{n}=8$, $\mathrm{p}<0.01)$.

Moreover, compared with the ketamine group, we found that pretreated with $5 \mu \mathrm{g} / \mathrm{kg} \mathrm{DEX}$ or $10 \mu \mathrm{g} / \mathrm{kg}$ DEX before ketamine anesthesia significantly decreased the proportion of $\beta$-tubulin $\mathrm{III}^{+} / \mathrm{BrdU}^{+}$cells in the SVZ compared with ketamine treatment (median [IQR]: $15.6 \%$ [14.85\%-16.05] in the $5 \mu \mathrm{g} / \mathrm{kg}$ DEX plus ketamine group, median [IQR]: 13.85 [13.125-14.175] in the $10 \mu \mathrm{g} / \mathrm{kg}$ DEX plus ketamine group, vs. median [IQR]: 19.05\% [18\%-19.725\%] in the ketamine group, $n=8, p<0.01$, Fig. 2A and 2B). In addition, pretreated with $\mathrm{DEX}$ could dose-dependently improve the reduction in the proportion of $\mathrm{GFAP}^{+} / \mathrm{BrdU}^{+}$cells in the SVZ under ketamine anesthesia (median [IQR]: $13.7 \%$ [12.88\%-13.98] in the $5 \mu \mathrm{g} / \mathrm{kg}$ DEX plus ketamine group, median [IQR]: 15.35 [14.93-15.68] in the $10 \mu \mathrm{g} / \mathrm{kg}$ DEX plus ketamine group, vs. median [IQR]: $11.35 \%$ [10.775\%-11.975\%] in the ketamine group, $\mathrm{n}=8, \mathrm{p}<0.01$, Fig. 3A and 3B). However, $1 \mu \mathrm{g} / \mathrm{kg}$ DEX pretreatment had no protective effect on the disturbance of proliferation and differentiation of NSCs induced by ketamine ( $p>0.05$, Fig. 1F, Fig. $2 B$ and $3 B$ ).

In summary, these results suggest that moderate and high-dose DEX pretreatment may alleviate the disturbance in the proliferation and differentiation of NSCs in the SVZ induced by ketamine. 


\section{Discussion}

Ketamine is a dissociative anesthetic and commonly used in pediatric anesthesia. An increasing preclinical evidence suggested that ketamine may causes neurodegeneration and neuroapoptosis in the developing brain and precipitate significant long-term cognitive sequelae in rodents and nonhuman primates. Epidemiological evidence has indicated that long-term neurotoxicity may ensue following prolonged and/or repeated exposure to ketamine in early life. The U.S. Food and Drug Administration (FDA) had issue the warning about prolonged and/or repeated exposure to general anesthetics may have a negative impact on developing children's brain[20].

Neurogenesis is an important process that occurs in multiple brain regions during the embryonic to adult stages, especially in the hippocampal dentate gyrus (DG) and subventricular zone (SVZ) [17-18]. The normal proliferation and differentiation of NSCs maintain a balance between the types and numbers of cells in the brain, which are the origin of neurons and glial cells. In rodents, the large number of neurons were established during gestation and extends for the first 21 postnatal days, which play a critical role in the formation of neural networks and neurocognitive functions. Our previous findings suggested that neonatal ketamine exposure disrupted the proliferation and differentiation of developmental NSCs in the hippocampal DG and caused hippocampus-dependent spatial memory dysfunction during the adult stage [5].

During the developmental neurogenesis in the SVZ, newly generated neurons migrate along the rostral migratory stream (RMS) to the olfactory bulb (OB), where the neurons were incorporated into the existing neural circuits and played a crucial role in long-term olfactory recognition memory [21-22]. Previous studies had suggested that early disruption of SVZ neurogenesis had the potential to alter the formation of neural circuit [23] and olfactory cognitive function during the adult stage [24]. This study demonstrated that ketamine exposure $(40 \mathrm{mg} / \mathrm{kg} \times 4)$ during the developmental stage significantly inhibited NSCs proliferation and astrocytic differentiation and promoted neuronal differentiation in the SVZ, which were consistent with our previous findings about fates of NSCs in the hippocampal DG and SVZ [5, 25].

During clinical anesthesia procedure, the safe anesthetics including neuroprotective effects have been widely investigated to avoid the adverse neurological effects of conventional anesthetics. The $\mathrm{a}_{2}{ }^{-}$ adrenoceptor agonist dexmedetomidine (DEX) IS A POPULAR WIDELY STUDIED anesthetic adjuvant DRUG IN RECENT YEARS, WHICH can produce sedative, analgesic, sympatholytic and anxiolytic properties during the perioperative period. At present, at least three different $a_{2}$ receptors $\left(a_{2 A}, a_{2 B}\right.$ and $a_{2 C}$ ) have been identified based on pharmacological and molecular biological probes [26]. Evidences had shown that $a_{2 A}$ subtype had a close relevance regarding sedation, analgesia, neuroprotection and sympatholysis [27]. The role of DEX in neonatal intensive care medicine and pediatric anesthesia has been an interesting topic of research in recent years. In preclinical studies, DEX has caught the attention of researchers and clinicians because it could produce neuroprotective properties on hippocampal neurogenesis and neuronal plasticity in the model of neonatal brain injury [28]. 
In the study regarding anesthetic-induced developmental neurotoxicity, DEX has been proven to produce neuroprotective effects on anesthetic-induced neurodegeneration and neuroapoptosis in the developing brain $[13,14,29-31]$. A recent in vitro study demonstrated that DEX could protect embryonic cortex NSCs from ketamine-induced injury [32]. Although DEX has been extensively studied as a clinical anesthetic adjuvant DRUG, its neuroprotective effects on the proliferation and differentiation of NSCs exposed to ketamine are poorly understood at the animal level. In this study, the dose of DEX was based on clinical concentrations that had been used in children $(1 \mu \mathrm{g} / \mathrm{kg})$ [33] or had been shown to mediate neuroprotective effects in animal experiments $(5 \mu \mathrm{g} / \mathrm{kg}, 10 \mu \mathrm{g} / \mathrm{kg})[34,35]$. One key finding of this work was ketamine-induced disturbence of proliferation and differentiation of NSCs in the SVZ could be largely reversed by a single pretreatment of DEX at intermediate $(5 \mu \mathrm{g} / \mathrm{kg})$ or high doses $(10 \mu \mathrm{g} / \mathrm{kg})$. However, the low-dose administration of DEX $(1 \mu \mathrm{g} / \mathrm{kg})$ did not produce potential neuroprotective effects.

\section{Conclusion}

The role of DEX has been an interesting topic of neonatological and pediatric anesthetic research in recent years. To define the neuroprotective effects of DEX, we investigated the implications of DEX in a repeated ketamine exposure model of the developing rat brain with a focus on SVZ neurogenesis. In conclusion, the present findings preliminarily demonstrated that DEX protected against the disturbance of proliferation and differentiation of developmental NSCs in the SVZ induced by ketamine WITH A DOSEDEPENDENT. Before its safely and efficient application in clinical pediatric anesthesia, the mechanisms underlying the protective effects of DEX on ketamine-induced neurotoxicity require further experimental and clinical investigation.

\section{Abbreviations}

NSCs: neural stem cells; DEX: dexmedetomidine; SVZ: subventricular zone; PND-7: Postnatal day 7; BrdU: 5-bromo-2-deoxyuridine; DG: dentate gyrus; RMS: rostral migratory stream; OB: olfactory bulb.

\section{Declarations}

\section{Ethics approval and consent to participate}

All animal experiments were carried out according to the Guide for the Care and Use of Laboratory Animals of the National Institutes of Health (publication no. 85-23, revised 1985). The experiments were approved by the Institutional Animal Care and Use Committee of the Nanjing Medical University.

\section{Consent for publication}

Not applicable.

\section{Availability of data and material}


The data that support the findings of this study are available from the corresponding author if needed.

\section{Competing interests}

The authors declare that they have no competing interests.

\section{Funding}

This work was supported by the National Natural Science Foundation of China (81901100), Key young medical research program of Jiangsu Province (QNRC2016587). Funding body played no role in the design of the study and collection, analysis, and interpretation of data and in writing the manuscript.

\section{Authors' contributions}

Conceived and designed the experiments: $\mathrm{H}$ Huang, $\mathrm{HH}$ Sha and PP Peng; Performed the experiments: $\mathrm{HH}$ Sha, PP Peng, B Li, GH Wei, J Wang; Data analysis and interpretation: HH Sha, PP Peng, H Huang and YQ Wu; Contributed reagents/materials/analysis tools: YQ Wu; Manuscript preparation: HH Sha, PP Peng and $\mathrm{H}$ Huang. All authors read and approved the final manuscript.

\section{Acknowledgements}

Not applicable.

\section{References}

1. Asadi P, Ghafouri HB, Yasinzadeh M, Kasnavieh SM, Modirian E. Ketamine and atropine for pediatric sedation: a prospective double-blind randomized controlled trial. Pediatr Emerg Care, 2013; 29: 136139.

2. Cevik B , Tuncer M , Erkal KH, Eryildirim B, Sarica K. Procedural sedation and analgesia for pediatric shock wave lithotripsy: a 10 year experience of single institution. Urolithiasis, 2018; 46(4): 363-367.

3. Zou X, Patterson TA, Sadovova N, Twaddle NC, Doerge DR, Zhang X, Fu X, Hanig JP, Paule MG, Slikker W, Wang C. Potential neurotoxicity of ketamine in the developing rat brain. Toxicol Sci, 2009; 108: 149-158.

4. Paule MG, Li M, Allen RR, Liu F, Zou X, Hotchkiss C, Hanig JP, Patterson TA, Slikker W Jr, Wang C. Ketamine anesthesia during the first week of life can cause long-lasting cognitive deficits in rhesus monkeys. Neurotoxicol Teratol, 2011; 33: 220-230.

5. He Huang, Cun-Ming Liu, Jie Sun, Ting Hao, Chun-Mei Xu, Dan Wang ${ }^{2}$, Yu-QingWu. Ketamine Affects the Neurogenesis of the Hippocampal Dentate Gyrus in 7-Day-Old Rats. Neurotox Res, 2016; 30: 185198.

6. Dong C, Rovnaghi CR, Anand KJ. Ketamine alters the neurogenesis of rat cortical neural stem progenitor cells. Crit Care Med, 2012; 40: 2407-2416. 
7. Asadi P, Ghafouri HB, Yasinzadeh M, Kasnavieh SM, Modirian E. Ketamine and atropine for pediatric sedation: a prospective double-blind randomized controlled trial. Pediatr Emerg Care, 2013; 29: 136139.

8. Wilder RT, Flick RP, Sprung J, Katusic SK, Barbaresi WJ, Mickelson C, Gleich SJ, Schroeder DR, Weaver AL, Warner DO. Early exposure to anesthesia and learning disabilities in a population-based birth cohort. Anesthesiology, 2009; 110: 796-804.

9. O'Mara K, Gal P, Ransommd JL, Wimmermd JE Jr., Carlosmd RQ, Dimaguilamd MA, Davonzomd C, Smithmd M. Successful use of dexmedetomidine for sedation in a 24-week gestational age neonate. Ann Pharmacother, 2009; 43: 1707-1713.

10. Potts AL, Anderson BJ, Warman GR, Lerman J, Diaz SM, Vilo S. Dexmedetomidine pharmacokinetics in pediatric intensive care-a pooled analysis. Paediatr Anaesth, 2009; 19: 1119-1129.

11. Petroz GC, Sikich N, James M, van Dyk H, Shafer SL, Schily M, Lerman J. A phase I, two-center study of the pharmacokinetics and pharmacodynamics of dexmedetomidine in children. Anesthesiology, 2006; 105: 1098-1110.

12. Pickard A, Davies P, Birnie K, Beringer R (2014) Systematic review and meta-analysis of the effect of intraoperative alpha(2)-adrenergic agonists on postoperative behaviour in children. $\mathrm{Br} \mathrm{J}$ Anaesth 112: 982-990.

13. Sanders RD, Xu J, Shu Y, Januszewski A, Halder S, Fidalgo A, Sun P, Hossain M, Ma D, Maze M: Dexmedetomidine attenuates isoflurane-induced neurocognitive impairment in neonatal rats. Anesthesiology 2009;110:1077-1085.

14. Sanders RD, Sun P, Patel S, M. LI, Maze M, D. MA: Dexmedetomidine provides cortical neuroprotection: impact on anaesthetic-induced neuroapoptosis in the rat developing brain. Acta Anaesthesiol Scand, 2010; 54: 710.

15. Tosun Z, Akin A, Guler G, Esmaoglu A, Boyaci A. Dexmedetomidine-ketamine and propofol-ketamine combinations for anesthesia in spontaneously breathing pediatric patients undergoing cardiac catheterization. J Cardiothorac Vasc Anesth, 2006; 20: 515-519.

16. Levänen J, Mäkelä ML, Scheinin H. Dexmedetomidine premedication attenuates ketamine-induced cardiostimulatory effects and postanesthetic delirium. Anesthesiology, 1995; 82: 1117-1125.

17. Fan $\mathrm{H}, \mathrm{Gao} \mathrm{J}$, Wang W, Li X, Xu T, Yin X. Expression of NMDA receptor and its effect on cell proliferation inthe subventricular zone of neonatal rat brain. Cell Biochem and Biophys, 2012; 62: 305-316.

18. Guidi S, Ciani E, Severi S, Contestabile A, Bartesaghi R. Postnatal neurogenesis in the dentate gyrus of the guinea pig. Hippocampus, 2005; 15: 285-301.

19. Porzionato A, Macchi V, Zaramella P, Sarasin G, Grisafi D, Dedja A, Chiandetti L, De Caro R. Effects of postnatal hyperoxia exposure on the rat dentate gyrus and subventricular zone. Brain Struct Funct, 2013; 220(1): 229-247.

20. Andropoulos DB, Greene MF. Anesthesia and developing brains-implications of the FDA warning. N Engl J Med, 2017; 376(10): 905-907. 
21. So K, Moriya T, Nishitani S, Takahashi H, Shinohara K. The olfactory conditioning in the early postnatal period stimulated neural stem/progenitor cells in the subventricular zone and increased neurogenesis in the olfactory bulb of rats. Neuroscience, 2008; 151: 120-128.

22. Sultan S, Mandairon N, Kermen F, Garcia S, Sacquet J, Didier A. Learning-dependent neurogenesis in the olfactory bulb determines long-term olfactory memory. FASEB J, 2010; 24: 2355-2363.

23. Schafer D, Lehrman E, Kautzman A, Koyama R, Mardinly A, Yamasaki R, Stevens B. Microglia sculpt postnatal neural circuits in an activity and complement-dependent manner. Neuron, 2012; 74: 691705.

24. Schinder AF, Gage FH. A hypothesis about the role of adult neurogenesis in hippocampal function. Physiology, 2004; 9: 253-261.

25. Huang H, Liu L, Li B, Zhao PP, Xu CM, Zhu YZ, Zhou CH, Wu YQ. Ketamine interferes with the proliferation and differentiation of neural stem cells in the subventricular zone of neonatal rats. Cell Physiol Biochem, 2015; 35(1): 315-25.

26. Coursin, DB, Coursin, DB, Maccioli, GA. Curr. Opin. Crit. Care, 2001; 7 (4): 221-226.

27. Ma, D, Hossain, M, Rajakumaraswamy, N, Arshad, M, Sanders, RD, Franks, NP. Dexmedetomidine produces its neuroprotective effect via the alpha 2A-adrenoceptor subtype. Eur. J. Pharmacol, 2004; 502 (1-2): 87-

28. Stefanie Endesfelder, Hanan Makki, Clarissa von Haefen, Claudia D. Spies, Christoph Bu“hrer, Marco Sifringer. Neuroprotective effect of dexmedetomidine against hyperoxia-induced injury in the developing rat brain. PLoS ONE, 12(2): e0171498.

29. Azeem Alam, Ka Chun Suen, Zac Hana, Robert D. Sanders, Mervyn Maze, Daqing Ma. Neuroprotection and neurotoxicity in the developing brain: an update on the effects of dexmedetomidine and xenon. Neurotoxicology and Teratology, 2017; 60: 102-116.

30. Liao Z, Cao D, Han X, Liu C, Peng J, Zuo Z, Wang F, Li Y: Both JNK and P38 MAPK pathways participate in the protection by dexmedetomidine against isoflurane-induced neuroapoptosis in the hippocampus of neonatal rats. Brain Res Bull, 2014; 107: 69-78.

31. Duan X, Li Y, Zhou C, Huang L, Dong Z: Dexmedetomidine provides neuroprotection: impact on ketamine induced neuroapoptosis in the developing rat brain. Acta Anaesthesiol Scand, 2014; 58 : 1121-1126.

32. Pan Lu, Shan Lei, Wei-song Li, Yang Lu, Juan Zheng, Ning Wang, Yong-jun Xia, Haixia Lu, Xinlin Chen, Yong Liu, Pengbo Zhang. Dexmedetomidine Protects Neural Stem Cells from Ketamine-Induced Injury. Cell Physiol Biochem, 2018; 47: 1377-1388.

33. Siddappa R, Riggins J, Kariyanna S, Calkins P, Rotta AT. High-dose dexmedetomidine sedation for pediatric MRI. Paediatr Anaesth, 2011; 21: 153-158.

34. Tachibana K, Hashimoto T, Kato R, Uchida Y, Ito R, Takita K. Neonatal administration with dexmedetomidine does not impair the rat hippocampal synaptic plasticity later in adulthood. Paediatr Anaesth, 2012; 22: 713-719. 
35. Laudenbach V, Mantz J, Lagercrantz H, Desmonts JM, Evrard P, Gressens P. Effects of alpha (2)adrenoceptor agonists on perinatal excitotoxic brain injury: comparison of clonidine and dexmedetomidine. Anesthesiology, 2002; 96: 134-141.

\section{Figures}

CON
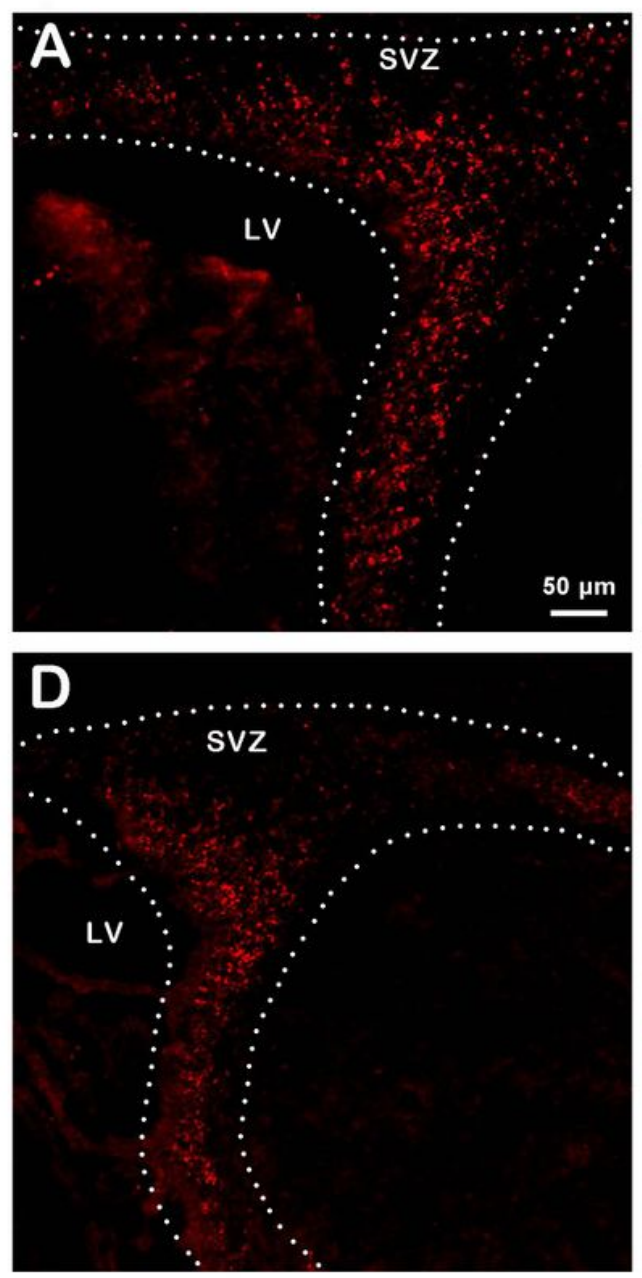

KET+DEX 5
KET

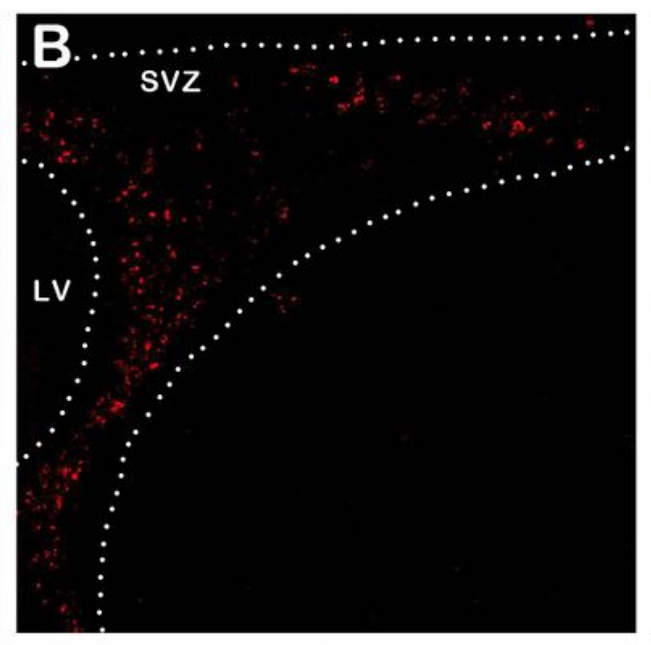

E

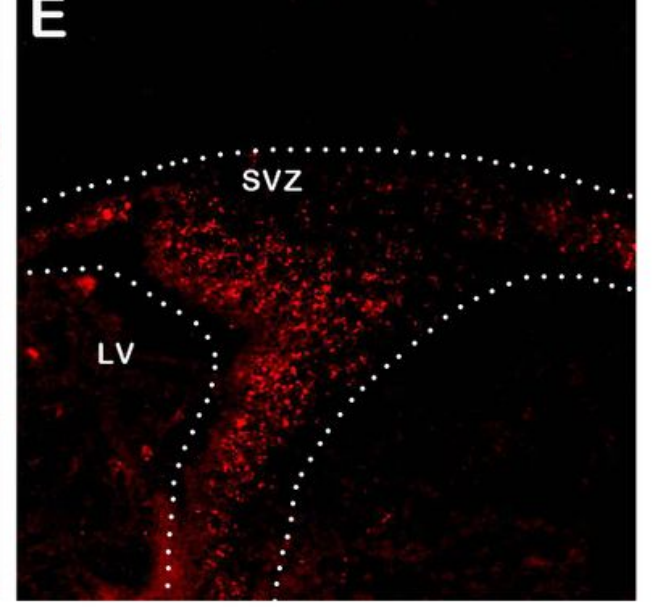

KET+DEX 10
KET+DEX 1

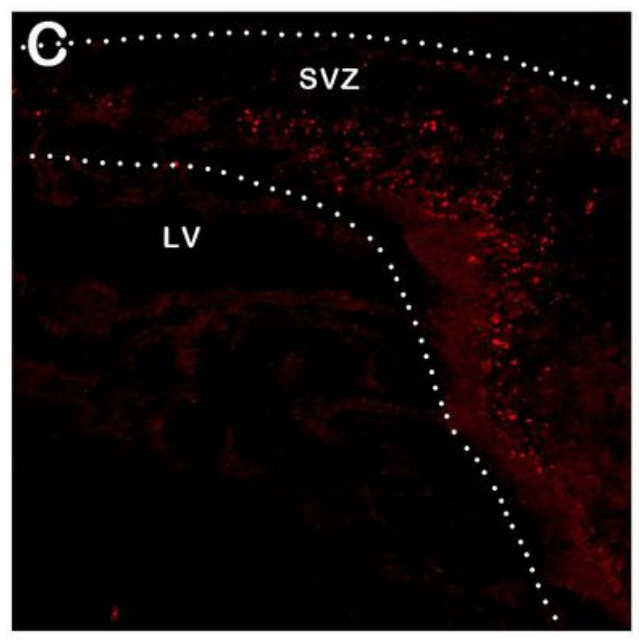

$\mathbf{F}$

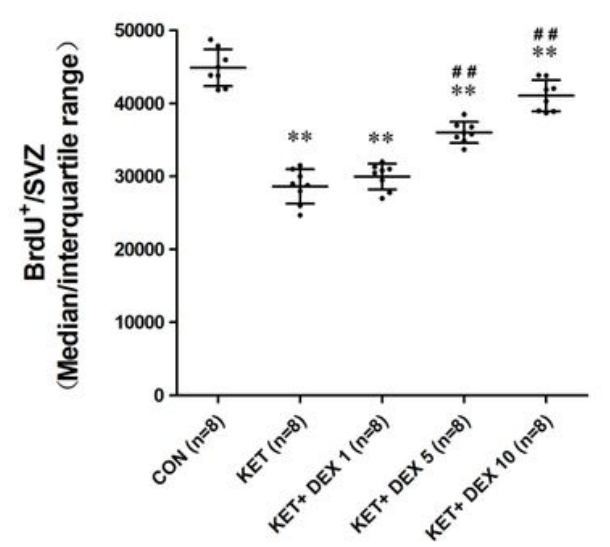

\section{Figure 1}

The effects of ketamine and dexmedetomidine (DEX) on the proliferation of neural stem cells (NSCs) in the SVZ. The neonatal rats were pretreated with different doses of DEX intraperitoneally prior to ketamine anesthesia for $30 \mathrm{~min}$. [A] Representative images of NSC proliferation (BrdU staining, red) were visualized using a laser scanning confocal microscope (magnification $\times 200$, scale bar: $50 \mu \mathrm{m}$ ). [B] The number of BrdU+ cells per SVZ in the different groups is expressed. Data are shown as the mean \pm SD (8 tissue sections per group). ${ }^{\star \star} p<0.01$ vs. control; $\# \# p<0.01$ vs. the ketamine group. $S V Z$ = subventricular zone; LV $=$ lateral ventricle. 
A

Merge $\quad \beta$-tubulin III

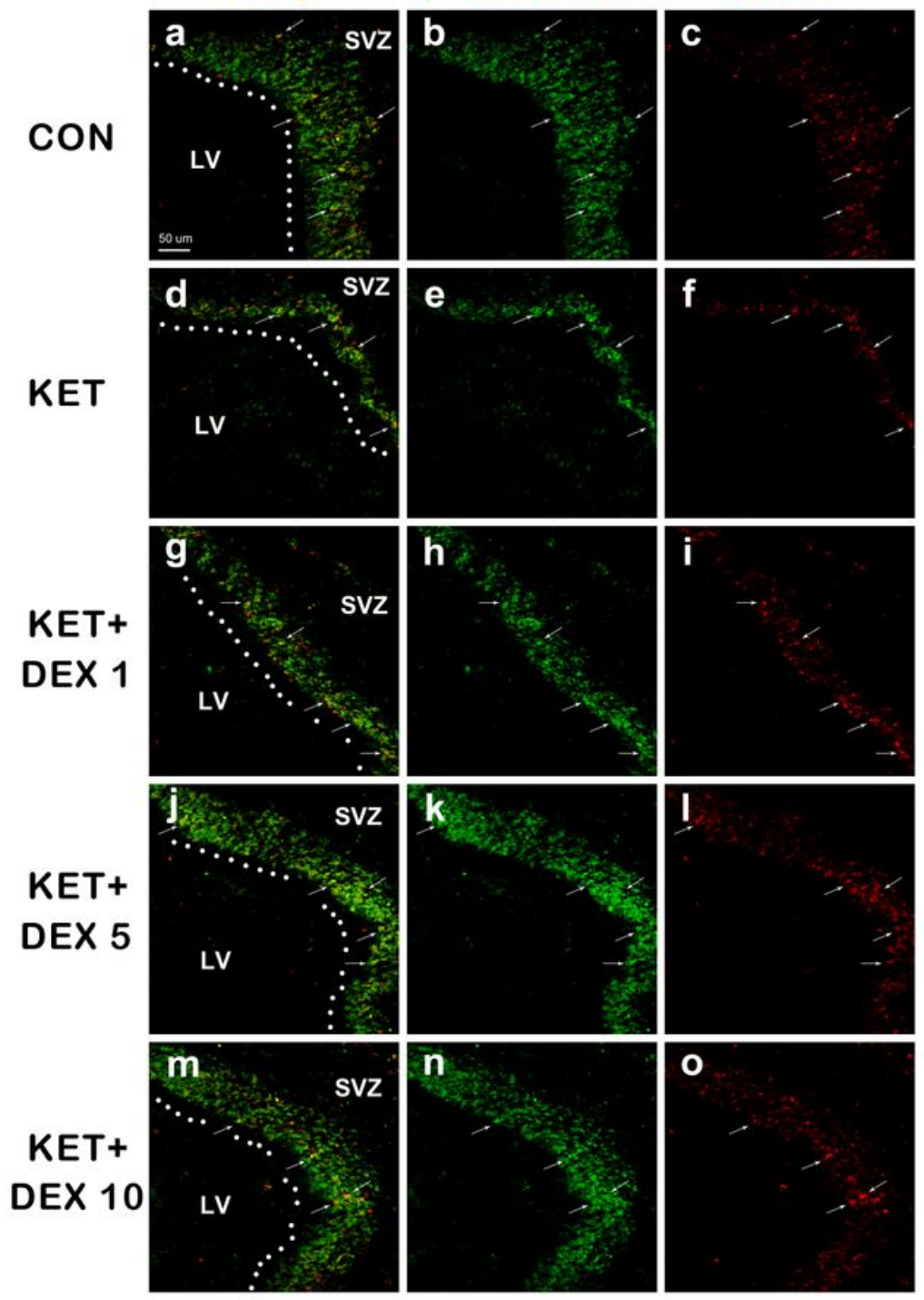

B

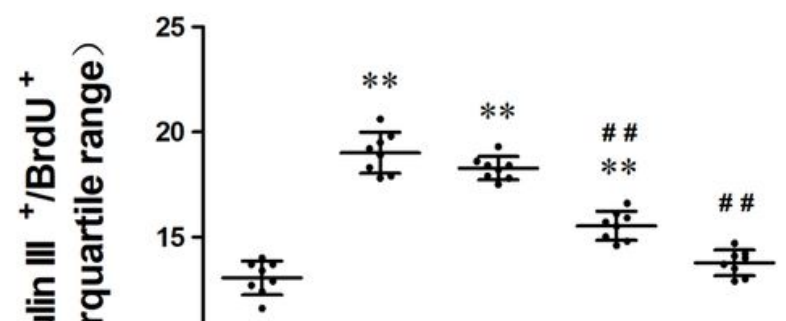

\section{Figure 2}

The effects of ketamine and dexmedetomidine (DEX) on the neuronal differentiation of neural stem cells (NSCs) in the SVZ. Neonatal rats were pretreated with different doses of DEX intraperitoneally prior to ketamine anesthesia for $30 \mathrm{~min}$. [A] Representative images of neuronal differentiation (BrdU, red; $\beta$ tubulin III, green) were visualized using a laser scanning confocal microscope (magnification $\times 400$, scale bar: $50 \mu \mathrm{m}$ ). [B] The proportion of $\beta$-tubulin III+/BrdU+ cells to BrdU+ cells per SVZ in the different groups are expressed. Data are shown as the mean \pm SD (8 tissue sections per group). ${ }^{\star \star} p<0.01$ vs. control; $\# \# p<0.01$ vs. the ketamine group. $S V Z=$ subventricular zone; $L V=$ lateral ventricle. 
A

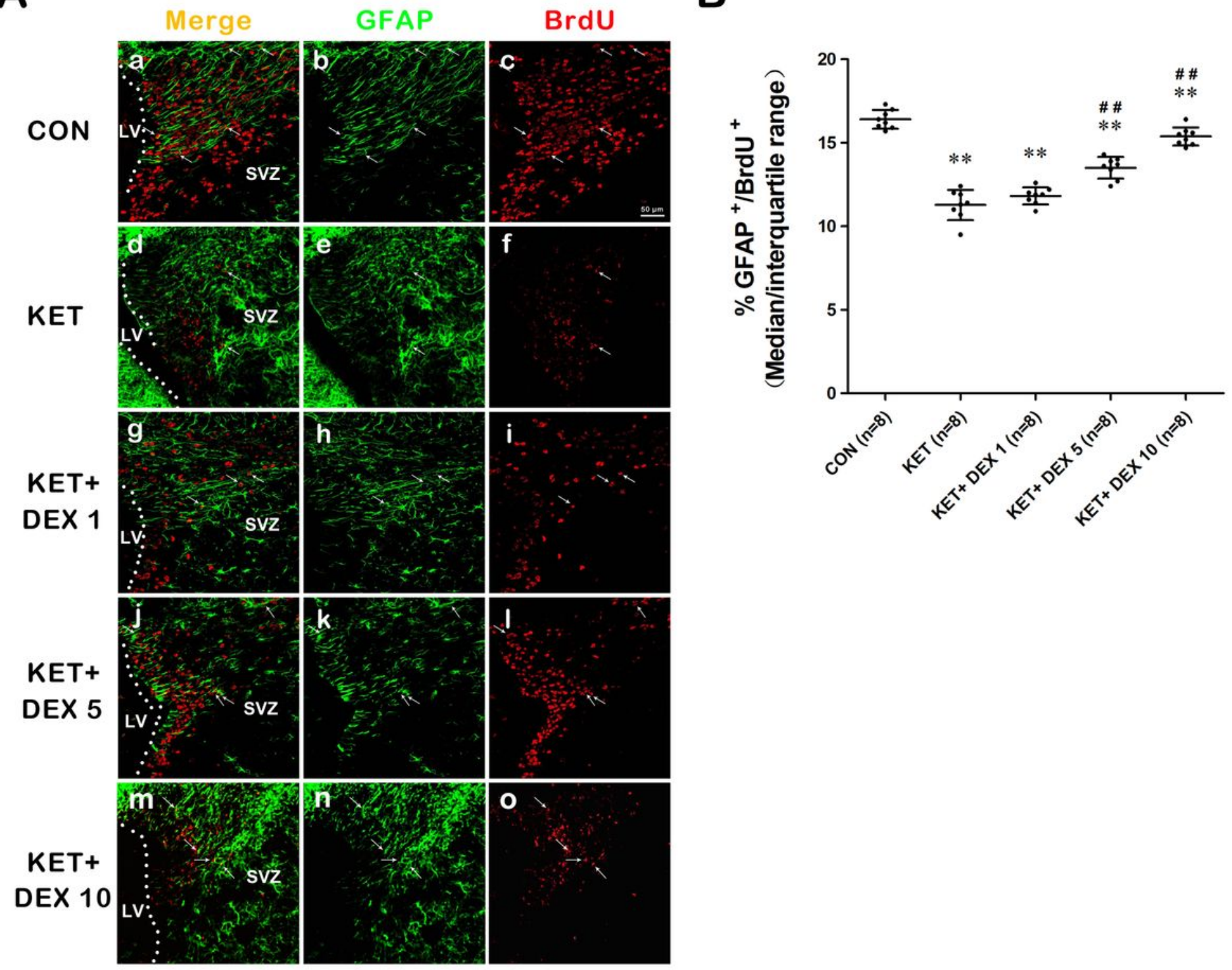

Figure 3

The effects of ketamine and dexmedetomidine (DEX) on the astrocytic differentiation of neural stem cells (NSCs) in the SVZ. Neonatal rats were pretreated with different doses of DEX intraperitoneally prior to ketamine anesthesia for $30 \mathrm{~min}$. [A] Representative images of astrocytic differentiation (BrdU, red; GFAP, green) were visualized using a laser scanning confocal microscope (magnification $\times 400$, scale bar: 50 $\mu \mathrm{m})$. [B] The proportion of GFAP+/BrdU+ cells to BrdU+ cells per SVZ in the different groups are expressed. Data are shown as the mean \pm SD (8 tissue sections per group). ${ }^{\star *} p<0.01$ vs. control; $\# \# p<0.01$ vs. the ketamine group. $S V Z=$ subventricular zone; $L V=$ lateral ventricle.

\section{Supplementary Files}

This is a list of supplementary files associated with this preprint. Click to download.

- NC3RsARRIVEGuidelinesChecklistfillable.pdf 